\title{
Sentimentos maternos frente à descoberta do filho com microcefalia: desafios encontrados
}

\author{
Maternal feelings against the discovery of the child with microcephaly: found challenges
}

Sentimientos maternos ante el descubrimiento del niño con microcefalia: desafios

encontrados

Francinubia Nunes Barros ${ }^{1}$, Dannieli de Sousa Silva Rodrigues ${ }^{2}$, Jeyzianne Franco da Cruz Silva ${ }^{1}$, Hercules Pereira Coelho ${ }^{1 *}$, Janayle Kéllen Duarte de Sales ${ }^{1}$, Francielton de Amorim Marçal ${ }^{1}$, Dennis

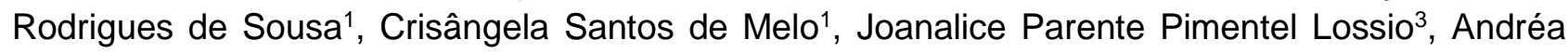
Couto Feitosa'.

\section{RESUMO}

Objetivo: Compreender os sentimentos maternos desencadeados frente à descoberta da microcefalia no filho. Métodos: Utilizou-se o método exploratório, descritivo, com abordagem qualitativa, o qual foi desenvolvido em uma instituição de saúde, considerada referência no atendimento à microcefalia, localizada no município de Barbalha, Ceará, Brasil. Resultados: No discurso das participantes, acerca dos sentimentos vivenciados, ao descobrir que o seu filho tinha microcefalia, foi notório a prevalência de emoções diversas, peculiares a cada participante, frente à descoberta da patologia no filho. Diante dos relatos maternos foi perceptível que não é fácil para a família, em especial, para a mãe, mudar de forma brusca a sua rotina, deixar o trabalho e estar periodicamente levando o filho para consultas, principalmente, quando este atendimento requer uma locomoção difícil para a família. Conclusão: A partir da pesquisa, pôde-se afirmar que o cotidiano de uma mulher, mãe de uma criança com microcefalia, é demasiadamente denso, pois são diversos os preconceitos presentes na sociedade, haja vista que esta passa a lidar com os aspectos da malformação e as dificuldades pós-hospitalares, que se tornam uma realidade complexa.

Palavras-chave: Microcefalia, Sentimentos, Mães.

\begin{abstract}
Objective: To understand the maternal feelings triggered by the discovery of microcephaly in the child. Methods: The method exploratory, descriptive, with qualitative approach was used, which was developed in a health institution, considered a reference in the care of microcephaly, located in the city of Barbalha, Ceará, Brazil. Results: In the discourse of participants about the feelings they experienced, when they discovered that their child had microcephaly, the prevalence of diverse emotions, peculiar to each participant, was noticeable when faced with the discovery of the pathology in the child. Given the maternal reports it was noticeable that it is not easy for the family, especially for the mother, to abruptly change her routine, to leave work and to be periodically taking her child to consultations, especially when this care requires a difficult locomotion to the family. Conclusion: From the research, it could be stated that the daily life of a woman, mother of a child with microcephaly, is too dense, because there are several prejudices present in society, because she starts to deal with aspects of malformation and posthospital difficulties, which become a complex reality.
\end{abstract}

Keywords: Microcephaly, Emotions, Mothers.

${ }^{1}$ Centro Universitário Doutor Leão Sampaio (UNILEÃO), Juazeiro do Norte - Ceará.

2 Universidade de Pernambuco (UPE), Recife - Pernambuco.

${ }^{3}$ Serviço Nacional de Aprendizagem Comercial (SENAC - CE), Juazeiro do Norte - Ceará.

*E-mail: herculesleon_01@yahoo.com 


\section{RESUMEN}

Objetivo: comprender los sentimientos maternos desatados por el descubrimiento de la microcefalia en el niño. Métodos: Utilizamos el método exploratorio, descriptivo y con enfoque cualitativo, que fue desarrollado en una institución de salud, considerada una referencia en atención de microcefalia, ubicado en el municipio de Barbalha, Ceará, Brasil. Resultados: En el discurso en los participantes sobre los sentimientos que experimentaron, cuando descubrieron que su hijo tenía microcefalia, la prevalencia de varias emociones era notoria, propias de cada participante, frente al descubrimiento de la patología en el niño. En frente a los informes maternos, se notó que no es fácil para la familia, especialmente para la madre, cambiar abruptamente su rutina, abandonar el trabajo y llevar periódicamente a su hijo a consultas, especialmente cuando este cuidado requiere movilidad difícil para la familia. Conclusión: De la investigación, se podría afirmar que la vida cotidiana de una mujer, madre de un niño con microcefalia, es demasiado densa, porque hay muchos prejuicios en la sociedad, dado que ahora se trata aspectos de malformación y dificultades poshospitalarios, que se convierten en una realidad compleja.

Palabras clave: Microcefalia, Emociones, Madres.

\section{INTRODUÇÃO}

A microcefalia é uma condição neurológica que ocorre quando o cérebro não se desenvolve de forma adequada, estando à periferia do crânio com tamanho menor que o esperado para idade. Crianças com este quadro detém um retardo no crescimento e desenvolvimento infantil (BRASIL, 2017). A Organização Mundial de Saúde (OMS) adota como modelo para a definição da microcefalia em recém-nascidos a termo o Perímetro Cefálico (PC) menor ou igual a $32 \mathrm{~cm}$ ao nascimento, enquanto que para os pré-termos toma-se o $\mathrm{PC}$ menor que dois centímetros do desvio padrão (BRASIL, 2015).

No período datado de 1952 a 1954 teve-se a notícia dos primeiros casos de infecção causados pelo Zika Vírus em humanos. Posteriormente, houve uma disseminação para o continente asiático, e no ano de 2005 a população internacional passou a ter maior conhecimento acerca deste vírus. Após o surto na Micronésia (ilha Yap, no Pacífico), em 2007, essa situação tornou-se ainda mais alarmante, bem como em 2012 e 2013 na Polinésia Francesa. A partir daí, casos notórios foram narrados em 2013 na Alemanha e em outros países (NUNES ML, et al., 2016). Após a observação do aumento exorbitante no número de casos de microcefalia, o governo brasileiro deu início a diversas investigações, principalmente no estado de Pernambuco, haja vista o mesmo apresentar notificações bem mais alarmantes sobre a patologia (SALGE AKM, et al., 2016; CAMARGO JÚNIOR KR, 2016).

A OMS convocou o Comitê Internacional de Emergência em Saúde e concluiu que as desordens neurológicas notificadas no Brasil e em outros países, no ano de 2016, em detrimento da alta incidência de quadros de microcefalia, são consideradas uma emergência de saúde pública de relevância internacional (HENRIQUES CMP, et al., 2016).

Para a mãe, o nascimento do filho é um acontecimento importante, principalmente quando é planejado e desejado. O vínculo entre eles se inicia desde o momento da concepção e vai aumentando a cada dia, juntamente com as mudanças que a mulher enfrenta no período gestacional. É comum que ela apresente sentimentos de medo e insegurança no período da gestação, por temer que o filho nasça com alguma máformação, em maior ou menor grau (SILVA HF e CAMILO JM, 2017).

Quando diagnosticado que o filho possui alguma deficiência, toda a família sofre um grande abalo, sendo, portanto, necessário, a união familiar, para que juntos consigam se adaptar, e aprendam a lidar com esta nova realidade (SILVA HF e CAMILO JM, 2017). Diante do problema abordado, intenta-se obter a resposta para os seguintes questionamentos: Qual o perfil sociodemográfico e econômico das participantes do estudo? Quais os sentimentos maternos após a descoberta da microcefalia no filho? Quais os principais desafios encontrados pelas mães de filhos com microcefalia?

A relevância do estudo é vislumbrada a partir das amplas discussões acerca do quadro de microcefalia que vêm sendo pautadas atualmente, somado ainda a carência de artigos científicos que abordem o assunto, e a necessidade de orientar as genitoras e familiares das crianças portadoras de microcefalia acerca dos 
principais sentimentos e desafios encontrados frente à busca pelo tratamento e manutenção da saúde. Assim, em razão da obtenção de mais estudos acerca da temática, faz-se necessário que os pesquisadores abordem mais sobre esta questão, para que os profissionais da saúde, bem como a sociedade, possam lidar melhor com esses casos, principalmente no que diz respeito às diversas reações sentimentais maternas ao receber uma criança portadora de tal limitação.

Assim, justifica-se a realização deste em detrimento de que nos últimos anos o Brasil, em especial o estado de Pernambuco, tem sido fortemente abalado pela alta incidência de casos de microcefalia, os quais têm se apresentado como um problema de saúde pública que necessita ser fortemente abordado dentro da classe dos profissionais da saúde, pesquisadores da área e temas afins.

Nesse contexto, a pesquisa surgiu a partir da reflexão sobre os principais sentimentos aflorados e as dificuldades perpassadas pelas mães cujos filhos têm microcefalia, bem como todas as nuances da fase de adaptação familiar e social, e propõe como objetivo compreender os principais sentimentos maternos desencadeados frente à descoberta da microcefalia no filho.

\section{MÉTODOS}

Trata-se de um estudo exploratório, descritivo, com abordagem qualitativa, realizado em uma instituição de saúde, considerada referência no atendimento à microcefalia, localizada no município de Barbalha, Ceará, Brasil. A população do estudo foi composta por 25 genitoras das crianças atendidas na supracitada instituição de saúde. Foram elencados como critérios de inclusão: genitoras de crianças com diagnóstico de microcefalia, acompanhadas na instituição de saúde. Ao passo que como critérios de exclusão foram estabelecidos: mães que não estavam presentes no momento da coleta de dados, e parentes de primeiro, segundo e terceiro grau que estivessem acompanhando a criança com microcefalia devido à ausência materna.

Após aplicação dos critérios de inclusão e exclusão, a amostra final do estudo foi composta por 18 mães. Tendo em vista nos dias de realização da entrevista, coleta dos dados, 7 mães não terem sido entrevistadas devido aos seguintes fatos: 1 criança estava de atestado médico, 2 crianças vieram acompanhadas da tia, 2 pacientes não estavam na lista de acompanhamento do núcleo, e as outras 2 faltaram ao atendimento agendado.

O instrumento utilizado para a coleta de dados foi um roteiro de entrevista estruturado, elaborado com perguntas objetivas de modo a obter melhores resultados diante do estudo, método este que contribuiu de modo pertinente perante a obtenção dos resultados. A coleta de dados foi realizada no mês de junho de 2017, de segunda a quinta-feira, no período da manhã, das 08 h00 às $12 \mathrm{~h} 00$. A apreciação dos dados teve como base a análise temática do conteúdo (MINAYO MCS, 2014). Os resultados da análise foram expostos através de categorias temáticas e discutidos à luz da literatura pertinente.

A pesquisa obedeceu a todos os aspectos éticos e legais estabelecidos pela Resolução oㅡ 466/12, do Conselho Nacional de Saúde, que regulamenta as normas e diretrizes de pesquisas envolvendo seres humanos (BRASIL, 2012). Deste modo, tendo em vista os aspectos éticos e legais, fez-se necessário a aplicação do Termo de Consentimento Livre Esclarecido, e, posterior, assinatura do Termo de Consentimento Pós-Esclarecido, firmando o consentimento legal para realização do estudo.

Com o intuito de assegurar o anonimato das participantes, os pesquisadores reservaram um breve momento para escolha dos codinomes representativos das mães, seguido do número em ordem crescente, dentre os quais podemos citar: Mãe 1, Mãe 2, Mãe 3, Mãe 4 [...]. O projeto de pesquisa foi aprovado pelo Comitê de Ética em Pesquisa do Centro Universitário Doutor Leão Sampaio - UNILEÃO, com o parecer consubstanciado de ํㅜㄴ.192.609.

\section{RESULTADOS}

A partir dos dados alcançados no estudo, tais como: características sociodemográficas e econômicas, e os discursos maternos acerca da microcefalia no filho, foi possível compreender os sentimentos aflorados nas mães e os principais desafios perpassados por estas. 
Os dados apresentados na (Tabela 1) revelam um predomínio de mães na faixa etária compreendida entre 18 a 25 anos, representada por $9(50 \%)$ da amostra total, seguida de mães entre 26 a 34 anos, caracterizada por $7(38,9 \%)$.

Ao investigar o nível de escolaridade das participantes do estudo, observa-se que das 18 participantes que constituíram a amostra somente $8(44,4 \%)$ possuíam o ensino médio completo. Quanto ao estado civil, verificou-se que $8(44,4 \%)$ participantes são casadas, resultado mais prevalente, e que apenas $3(16,7 \%)$ declararam ser solteiras. Em relação à raça, foi vislumbrado um quantitativo análogo de mulheres autodeclaradas negras $9(50 \%)$, e brancas $9(50 \%)$.

Tabela 1 - Distribuição das participantes de acordo com o perfil sociodemográfico e econômico, na Policlínica João Pereira dos Santos, em Barbalha, Ceará. Brasil. 2019.

\begin{tabular}{ccc}
\hline Variável & $\mathbf{n}$ & $\%$ \\
\hline Idade (em anos) & & \\
\hline $18-25$ & 9 & 50,0 \\
$26-34$ & 7 & 11,1 \\
Acima de 35 & 2 & 33,3 \\
\hline Escolaridade & 6 & 22,2 \\
\hline Fundamental Incompleto & 4 & 44,4 \\
Fundamental Completo & 8 & \\
Ensino Médio Completo & & 16,7 \\
\hline Estado Civil & 3 & 44,4 \\
\hline Solteira & 8 & 38.9 \\
Casada & 7 & 50,0 \\
Outros & & 50,0 \\
\hline Raça & 9 & 77,8 \\
Negra & 9 & 11,1 \\
Branca & & 11,1 \\
\hline Ocupação & 14 & \\
\hline Do lar & 2 & 16,3 \\
Autônoma & 2 & 100 \\
Outra & &
\end{tabular}

Fonte: Barros FN, et al., 2019.

No item relacionado à ocupação das genitoras do estudo, 14 (77,8\%) participantes afirmou ser do lar, dado este que chama atenção, pois reafirma a predominância da mulher na realização das tarefas do lar. No que tange à renda familiar, $15(83,3 \%)$ mães referiram ganhar até um salário mínimo, o que ressalta a baixa condição socioeconômica destas, ao passo que $3(16,7 \%)$ afirmaram deter uma renda mensal de 1 a 3 salários mínimos (Tabela 1).

Quando as entrevistadas foram questionadas acerca dos sentimentos vivenciados ao descobrir que o seu filho tinha microcefalia, as respostas a essa categoria nos permitiram perceber que as mães revelavam emoções diversas, e cada uma, em sua particularidade, definia os sentimentos de uma forma peculiar sobre o que vivenciou após a descoberta da patologia no filho. A seguir são apresentadas algumas falas das mães, com o intuito de analisar os resultados encontrados nesta pesquisa:

Categoria Temática 1: Os sentimentos maternos após a descoberta da microcefalia no filho:

"Na descoberta senti raiva, tristeza e um desespero grande" (Mãe 1).

"Tristeza, angústia, alegria, amor, carinho" (Mãe 2). 
"[...] Tive medo de perder o meu filho, medo de não poder ver ele crescer, mas hoje vendo ele, como está se desenvolvendo, meu sentimento é de alegria, felicidade [...]" (Mãe 3).

"De início angústia e medo do que eu iria enfrentar [...]" (Mãe 4).

"Primeiro caí no desespero, chorei muito, com o tempo já aceito muito bem ele" (Mãe 5).

"No início foi medo, passei pela fase de aceitação, e hoje aceito muito bem" (Mãe $6)$.

"Fiquei depressiva, fiz acompanhamento, e hoje aceito tudo normal" (Mãe 7).

No que se refere aos principais desafios encontrados pelas genitoras, muitas fizeram relatos que evidenciam a dificuldade de encontrar o tratamento necessário para o filho, como declarado nos discursos a seguir:

\section{Categoria Temática 2: Principais desafios encontrados pela mãe frente ao filho com microcefalia:}

"Inicialmente, ter que voltar para casa e deixar ele na UTI por 22 dias. [...] ter que tirar leite sem ele mamar [...]" (Mãe 8).

"Deixar de trabalhar e correr atrás de tratamento para ela" (Mãe 9).

"Primeiro foi largar o meu emprego, [...] aceitar minha filha do jeito que Deus mandou" (Mãe 10).

"A rotina que mudou, porque tenho que correr com ele para buscar o tratamento" (Mãe 11).

"O mais difícil foi conseguir acompanhamento para ele iniciar o tratamento [...]" (Mãe 12).

"[...] Encontrar profissionais capacitados" (Mãe 13).

"De início, dificuldade com o acesso ao tratamento" (Mãe 14).

"[...] Diferenças da sociedade [...]" (Mãe 15).

"Surgimento de preconceito diário, [...] locomoção" (Mãe 16).

"[...] Como eu precisava trabalhar não tinha quem ficasse com ela, as pessoas tinham medo" (Mãe 17).

"[...] Viagens muito longas, diagnóstico, mas hoje em dia estou superando tudo [...]" (Mãe 18).

\section{DISCUSSÃO}

Quanto à idade materna, os resultados caminham de encontro aos apresentados no estudo acerca dos coeficientes de prevalência e caracterização dos casos de microcefalia, que por meio dos dados secundários oriundos do Sistema de Informação de Nascidos Vivos (SINASC), relativo ao período de 2000 a 2015 , evidenciou que houve um predomínio de mães que tinham filhos com microcefalia com faixa etária de até 24 anos (MARINHO F, et al., 2016). O quantitativo de mães que referiram ter o ensino médio completo se sobressai de modo expressivo aos demais resultados, fato este que coincide com o estudo realizado por Cabral CM, et al. (2017), no qual foi avaliado as características clínicas e epidemiológicas dos casos de microcefalia em nascidos vivos no estado de Sergipe, Brasil, através dos prontuários dos nascidos vivos.

O predomínio de mulheres solteiras é abordado por Marinho $F$, et al. (2016), em seu estudo, o qual demonstra um percentual de $47 \%$ de mulheres solteiras, dado este que diverge do resultado encontrado na pesquisa, haja vista que esse público é representado por apenas 03 (16,7\%). Perante a raça materna, foi evidenciado um nível similar de variância entre negras e brancas, dado este que difere dos apresentados por Marinho F, et al. (2016), na qual $69,2 \%$ das participantes eram predominantemente autodeclaradas negras.

A participação da mulher nas atividades diárias do lar é reafirmada no estudo realizado por Cabral CM, et al. (2017), o qual evidencia que além do serviço do lar, as mulheres cuidam de uma criança que requer cuidados especiais na realização de algumas atividades, para que assim possam superar os limites estabelecidos pelo seu quadro clínico. 
A condição socioeconômica encontrada no estudo diverge dos resultados apontados por Marinho $\mathrm{F}$, et al. (2016), que em sua pesquisa, a partir de um comparativo entre a região Nordeste e outras regiões brasileiras, no ano de 2015, observou que no Nordeste houve um rendimento mensal inferior ao das demais regiões, sendo encontrado percentual de rendimento mensal de apenas $67 \%$, no ano em que sua pesquisa foi desenvolvida.

Ao descobrir a microcefalia no filho, frustra-se a idealização de filho constituída durante o período gestacional, ou até mesmo, durante toda a vida, ante a realidade da confirmação do diagnóstico do filho com tal patologia (MELO DGS, et al., 2017). Assim, a vivência das mães de filhos que têm microcefalia é um fenômeno marcado por história de dor, sofrimento, mágoa e superação, resultando para muitas na fortificação da resiliência, como é possível perceber em alguns dos relatos retratados pelas mães, os quais expressam a habilidade de se adequarem a tentativa de um novo caminhar (GUERRA CS, et al., 2015).

Para Matos MG, et al. (2017), o sentimento de tristeza, medo, angústia, desespero, entre outros, estão atrelados ao luto da parturição, processo este relacionado ao filho idealizado e sonhado. Nesse viés, as genitoras passam por diversas situações que as fortalecem a cada dia. A raiva é o segundo estágio do luto, que acontece quando a pessoa já não consegue sustentar a primeira fase, a negação. Destarte, para a mãe, em especial, o nascimento do filho portador de deficiência destrói o sonho do descendente real e, com ele, o desejo de tornar-se genitora (BARROS SMM, et al., 2017). Assim, o não entusiasmo de ter uma criança como idealizava é notório nos pais, especialmente na mãe, que apresenta um vazio momentâneo em seu ser, por não se sentir mãe. Porém, com o passar do tempo, e com a ajuda da família, a mesma vai aceitando o filho e a cada dia amando-o e superando as dificuldades da vida (SILVA HF e CAMILO JM, 2017).

O sentimento negativo que surge no nascimento de um filho, com malformação congênita, irá interferir na relação do binômio mãe-filho, uma vez que este sentimento será uma barreira para a genitora cuidar de sua prole (MELO DGS, et al., 2017). A fase de aceitação mencionada pelas mães é de suma importância, visto que é nessa fase que ocorre a construção de um vínculo entre a díade mãe e filho, o qual, até então, estava enfraquecido devido ao processo do luto materno e familiar. Quando a mãe alcança a aceitação, começa a inserir o filho na sociedade, quebrando os paradigmas e preconceitos previamente estabelecidos (GUERRA CS, et al., 2015). Como visto anteriormente, a descoberta da malformação do filho e a vivência do luto marcam a relação da mãe com o filho por toda a vida, isso se dá devido à veemência das dificuldades encontradas, visto que, nos momentos iniciais, é muito difícil para a mãe lidar com o filho com microcefalia e investir no seu crescimento (BARROS SMM, et al., 2017).

Em seus estudos, Freitas AAF (2018) afirma que a mãe precisa trabalhar para que possa contribuir com a renda familiar, bem como, que o trabalho é uma maneira de obter satisfação pessoal. Desse modo, nota-se ainda nos discursos das participantes da pesquisa a dificuldade de transporte, acesso ao tratamento, e a necessidade de ausentar-se das atividades trabalhistas, em detrimento da carência de cuidadores capacitados para cuidar do filho com microcefalia, e os problemas de locomoção para o tratamento deste, da mesma maneira a insuficiência de profissionais da saúde capacitados para atender às crianças portadoras de tal quadro clínico.

$\mathrm{Na}$ realidade, as genitoras de crianças portadoras de microcefalia devem ter acesso ao ambiente terapêutico que Ihe irradie segurança nas informações fornecidas pela equipe multidisciplinar que acompanha o seu filho, pois é durante as consultas clínicas que as mães podem ser orientadas acerca desta patologia e, consequentemente, cuidar melhor da criança (SOUZA SM, et al., 2017). Em seus estudos, Oliveira IG e Poletto M (2015) elucidam que essa dificuldade ocorre devido ao fato de que a criança pode necessitar de alguns cuidados e modificações, as quais, de início, a genitora não sabe como lidar, tais como: adaptação na residência, tratamentos diversos, aprender uma nova forma de se comunicar com o filho, e algumas vezes, o auxílio de transporte para se locomover com o mesmo, pois demora um certo tempo até que ela e toda a família se adapte a essa nova fase.

Diante do exposto, verifica-se que não é fácil para a família, em especial para a mãe, mudar de forma brusca a sua rotina, deixar o trabalho e estar periodicamente levando o filho para consultas, principalmente quando este atendimento requer uma locomoção difícil para a família. 
Nesse contexto, conforme o Projeto de Lei de ํㅜ 4.482 do ano de 2016, o governo disponibiliza benefícios às pessoas com microcefalia decorrentes do Zika Vírus, o qual determina o Fundo Nacional de Apoio às Vítimas de Microcefalia (FNAVM). Este auxílio de custo é de grande valia para estas famílias, visto que a maior parte da população atingida por esta patologia é economicamente carente (BARBOSA LA e BEM IP, 2018).

\section{CONCLUSÃO}

No estudo, pôde-se concluir que houve uma grande similaridade entre os sentimentos evidenciados pelas mães ao receberem o diagnóstico da microcefalia do filho, dentre eles: medo, raiva, angústia, depressão, desespero, medo de perder o filho, amor, carinho e aceitação. Observa-se que um grande quantitativo das mães expressou que uma das maiores dificuldades vivenciadas é de encontrar um local para que o filho inicie o tratamento. Desenvolver um estudo que vise compreender sentimentos não é tarefa fácil, principalmente por tratar-se de impressões tão subjetivas e pessoais como o sentimento materno frente à descoberta do filho com microcefalia. Não há linearidade nesta análise, pois o modo como cada mãe reage aos desafios impostos pelas limitações de um filho com tal patologia oscila demasiadamente.

\section{REFERÊNCIAS}

1. BARBOSA LA, BEM IP. Microcefalia pelo Zika Vírus: as ações do poder legislativo e executivo brasileiro no combate à epidemia. Rev Cad. Ibero-Amer. Dir. Sanit., Brasília, 7(1):127-146, jan./mar. 99999

2. BARROS SMM, et al. Fortalecendo a Rede de Apoio de Mães no Contexto da Síndrome Congênita do Vírus Zika: relatos de uma intervenção psicossocial e sistêmica. Rev Nova perspect. sist. [online]. vol.26, n.58, pp. 38-59. 2017.

3. BRASIL. Conselho Nacional de Saúde. Resolução no 466, de 12 de dezembro de 2012. 2012.

4. BRASIL. Fundação Osvaldo Cruz - FIOCRUZ. Vírus Zika e microcefalia. Rio de Janeiro, 2017.

5. BRASIL. Ministério da Saúde. Secretaria de Atenção à Saúde. Protocolo de Atenção à Saúde e Resposta à Ocorrência de Microcefalia Relacionada à Infecção pelo Vírus Zika. Ministério da Saúde, Secretaria de Atenção à Saúde - Brasília: Ministério da Saúde, 2015.

6. CABRAL CM, et al. Clinical-Epidemiological Description of Live Births with Microcephaly in the State of Sergipe, Brazil, 2015. Epidemiologia e Serviços de Saúde, v. 26, n. 2, p. 245-254, 2017.

7. CAMARGO JÚNIOR KR. Zika, Microcefalia, Ciência e Saúde Coletiva. Physis Revista de Saúde Coletiva, Rio de Janeiro, 26 [1]: 9-10, 2016.

8. FREITAS AAF. Avaliação do Impacto Familiar em Pais de Crianças Diagnosticadas com Microcefalia pelo Zika Vírus. PUC - Goiás. 2018.

9. GUERRA CS, et al. Do sonho à Realidade da Experiência de Mães de Crianças com Deficiência. Texto \& ContextoEnfermagem, v. 24, n. 2, p. 459-466. 2015.

10. HENRIQUES CMP, et al. Desafios para o Enfrentamento da Epidemia de Microcefalia. Epidemiol. Serv. Saúde [online]. 1679- 4974. vol. 25, n.1, pp.7-10. 2016.

11. MARINHO F, et al. Microcefalia en Brasil: prevalencia y caracterización de casos a partir del Sistema de Informaciones sobre Nacidos Vivos (Sinasc), 2000-2015. Epidemiol. Serv. Saúde, Brasília, v. 25, n. 4, p. 701-712, Dec. 2016.

12. MATOS MG, et al. Construindo o Vínculo Pai-Bebê: A Experiência dos Pais. REV. Psico-USF, Bragança Paulista, v. 22, n. 2, p. 261-271, mai./ago. 2017.

13. MELO DGS, et al. Aceitação Paterna Diante o Diagnóstico de Microcefalia. Rev Psicologia.pt. ISSN: 1646-6977. 2017.

14. MINAYO MCS. O Desafio do Conhecimento: pesquisa qualitativa em saúde. São Paulo; Hucitec; 14 ed.; p. 407.2014.

15. NUNES ML, et al. Microcephaly and Zika Virus: a clinical and epidemiological analysis of the current outbreak in Brazil. J. Pediatr. (Rio J.), Porto Alegre, v. 92, n. 3, p. 230-240, June. 2016.

16. OLIVEIRA IG, POLETTO M. Vivências Emocionais de Mães e Pais de Filhos com Deficiência. Rev. SPAGESP [online]. vol.16, n.2, pp. 102-119. 2015.

17. SALGE AKM, et al. Infecção pelo Vírus Zika na Gestação e Microcefalia em Recém-Nascidos: revisão integrativa de literatura. Rev. Eletr. Enf. [Internet]. 18: e 1137. 2016.

18. SILVA HF, CAMILO JM. Os Efeitos Colaterais da Culpa: mães de crianças microcefálicas sob o uso de anticonvulsivantes. Rev: Psicologia. pt. ISSN: 1646-6977. 2017.

19. SOUZA SM, et al. Microcefalia na Intervenção Precoce: estratégias eficazes de intervenção. Rev. UIIPS. Vol. 5, N.ำ $1: 46-61.2017$. 